\title{
Is There a Relationship Between Vitamin D Deficiency Status and PCOS in Infertile Women?
}

\section{Gibt es eine Beziehung zwischen Vitamin-D-Mangel und PCOS bei unfruchtbaren Frauen?}

(C) 9

\author{
Authors \\ Emine Arslan, Umit Gorkem, Cihan Togrul
}

Affiliation

Hitit University Faculty of Medicine, Department of Obstetrics and Gynecology, Corum, Turkey

Key words

vitamin D, polycystic ovary syndrome, PCOS, anti-Müllerian hormone, $\mathrm{AMH}$

Schlüsselwörter

Vitamin D, polyzystisches Ovarialsyndrom, PCOS,

Anti-Müller-Hormon, AMH

received $\quad 13.10 .2018$

revised 6.2.2019

accepted 7.3.2019

\section{Bibliography}

DOI https://doi.org/10.1055/a-0871-6831

Geburtsh Frauenheilk 2019; 79: 723-730 @ Georg Thieme

Verlag KG Stuttgart · New York | ISSN 0016-5751

Correspondence

Umit Gorkem, MD

Department of Obstetric and Gynecology, Hitit University

Faculty of Medicine

Inonu Street, Corum 19030, Turkey

drumitgorkem@hotmail.com

\section{ABSTRACT}

Introduction It is still unclear in the literature whether low vitamin D levels play a role in the pathogenesis of polycystic ovary syndrome (PCOS), especially with respect to the regulation of anti-Müllerian hormone (AMH). Therefore, we aimed to investigate whether there could be a relationship between vitamin D deficiency status and PCOS.

Materials and Methods A total of 146 infertile women were divided into two groups according to their ovarian reserve patterns: (i) normal (NOR), and (ii) high (PCOS). The participants were also categorized into two groups according to vitamin $D$ concentrations: (i) Group A $<10 \mathrm{ng} / \mathrm{mL}$, and (ii) Group B 10-
$20 \mathrm{ng} / \mathrm{mL}$. Samples were obtained and analyzed for estradiol (E2), follicle-stimulating hormone (FSH), luteinizing hormone (LH), total testosterone (TT), 17-hydroxyprogesterone (17OHP), dehydroepiandrosterone sulfate (DHEA-S) and AMH.

Results In the NOR group, there were significant differences between Group A and Group B in terms of anthropometric characteristics ( $p<0.05$, for all). The women in both Group $A$ and Group B had similar AMH concentrations ( $p>0.005)$. Only the NOR group showed a significant though moderate negative correlation between 25(OH)D levels and anthropometric parameters. AMH levels were not correlated with $25(\mathrm{OH}) \mathrm{D}$ levels in the NOR or the PCOS group $(r=-0.112, p=0.008$; $r=0.027, p=0.836$ ). Multivariate regression analysis showed no impact of 25(OH)D on other study parameters. Only AMH measurements were significant enough $(p<0.001)$ to differentiate between PCOS and NOR patterns.

Conclusion We found no difference in serum 25(OH)D and AMH levels between women with and women without PCOS. No correlation could be demonstrated between 25(OH)D and $\mathrm{AMH}$ in the PCOS group or controls.

\section{ZUSAMMENFASSUNG}

Einleitung In der Literatur ist immer noch unklar, ob ein niedriger Vitamin-D-Spiegel eine Rolle bei der Pathogenese von polyzystischem Ovarialsyndrom (PCOS) spielt, besonders in Bezug auf die Regulierung des Anti-Müller-Hormons (AMH). Ziel dieser Studie war es daher zu untersuchen, ob es eine Beziehung zwischen Vitamin-D-Mangel und PCOS gibt.

Material und Methoden Es wurden insgesamt 146 unfruchtbare Frauen in die Studie aufgenommen und entsprechend ihrer ovariellen Reserve in 2 Gruppen eingeteilt: (i) normale ovarielle Reserve (NOR), und (ii) hohe ovarielle Reserve (PCOS). Die Teilnehmerinnen wurden zusätzlich je nach Vitamin-D-Spiegel in 1 von 2 Gruppen unterteilt: (i) Gruppe A $<10 \mathrm{ng} / \mathrm{mL}$, und (ii) Gruppe B $10-20 \mathrm{ng} / \mathrm{mL}$. Den Teilnehmerinnen wurden Blutproben zur Bestimmung von Östradiol (E2), follikelstimulierendem Hormon (FSH), luteinisierendem Hormon (LH), Gesamttestosteron (TT), 17-Hydroxyprogesteron (17-OHP), Dehydroepiandrosteron-Sulfat (DHEA-S) und $\mathrm{AMH}$ entnommen. 
Ergebnisse In der NOR-Gruppe gab es signifikante Unterschiede zwischen Gruppe A und Gruppe B hinsichtlich der anthropometrischen Daten ( $p<0,05$, für alle Gruppen). Die $\mathrm{AMH}-$ Konzentrationen waren ähnlich für Frauen aus Gruppe A und Frauen aus Gruppe B ( $p>0,005)$. Nur bei der NORGruppe fand sich eine signifikante moderate negative Korrelation zwischen 25(OH)D-Spiegel und anthropometrischen Parametern. AMH-Werte korrelierten weder in the NOR-Gruppe noch in der PCOS-Gruppe mit 25(OH)D-Werten $(r=-0,112$, $p=0,008 ; r=0,027, p=0,836)$. Bei der multivariaten Regres- sionsanalyse zeigten sich keine Auswirkungen von 25(OH)DWerten auf andere Studienparameter. Nur die AMH-Werte waren signifikant genug $(p<0,001)$, um zwischen PCOS und NOR zu unterscheiden.

Schlussfolgerung Wir fanden keinen Unterschied in den 25(OH)D-Werten und den AMH-Werten zwischen Frauen mit und Frauen ohne PCOS. Es gab keine Hinweise auf eine Korrelation zwischen 25(OH)D-Werten und AMH-Werten in der PCOS-Gruppe und der Kontrollgruppe.

\section{Introduction}

Polycystic ovary syndrome (PCOS) is a common endocrinologic problem that affects $5-10 \%$ of women of reproductive age $[1,2]$. PCOS is a heterogeneous condition characterized by androgen excess and varying degrees of reproductive and metabolic dysfunction. PCOS appears to be associated with an increase in the number of antral follicles, possibly resulting from a specific defect of anti-Müllerian hormone (AMH) synthesis by granulosa cells [3, 4]. The high AMH levels, which are a main feature of PCOS, appear to be related to the pathogenesis of PCOS.

Vitamin $D$ is produced following the conversion of 7-dehydrocholesterol in the skin through ultraviolet-B radiation. Vitamin D undergoes two hydroxylation processes that yield 25-hydroxyvitamin D [25(OH)D] and 1,25 dihydroxyvitamin D. As 25(OH)D is an easily measured molecule with a long half life, it is considered to be the best indicator of vitamin D status in humans [5].

Vitamin $\mathrm{D}$ is the main regulator of calcium/phosphorus homeostasis and bone structure. Vitamin D is thought to organise gene transcriptions via vitamin $D$ receptors. These receptors are present in many tissues of the body including the ovaries [6]. Vitamin D deficiency appears to contribute to the pathogenesis of PCOS. However, there is no consensus about the importance of serum vitamin D levels in women with PCOS [7, 8].

Although the prevalence of vitamin D deficiency in women with PCOS continues to be a controversial issue, it is a common problem in the general population, with an estimated prevalance of $10-60 \%[9,10]$. In a study by Thomson et al., $67-85 \%$ of women with PCOS had vitamin D deficiency, with levels of less than $20 \mathrm{ng} / \mathrm{mL}$ [8]. In Turkey, as in other countries around the world, vitamin D deficiency is endemic. Authors in a recent study claimed that $94.47 \%$ of women living in Turkey had serum 25(OH)D levels of less than $30 \mathrm{ng} / \mathrm{ml}, 76.25 \%$ had serum $25(\mathrm{OH}) \mathrm{D}$ levels of less than $20 \mathrm{ng} / \mathrm{ml}$, and $32.20 \%$ had serum $25(\mathrm{OH}) \mathrm{D}$ levels of less than $10 \mathrm{ng} / \mathrm{ml}[11]$.

A number of studies have implied that there may be an association between low vitamin D status and PCOS. Lower vitamin D levels were found in women with PCOS compared to controls in several studies $[12,13]$. Moreover, vitamin D deficiency may be a contributing factor to aspects of metabolic syndrome which are commonly observed in women with PCOS $[10,14]$. Lastly, it has been suggested that vitamin D supplementation could improve menstrual irregularity, follicular development and pregnancy rates in women with PCOS $[15,16]$.
The existing literature provides some consistent evidence about the relationship between vitamin D status and PCOS. Previous studies have reported that women with PCOS frequently present with vitamin D deficiency $[10,13,17]$. Another study proposed that vitamin $\mathrm{D}$ receptor polymorphism could play a part in the pathogenesis of PCOS [18]. However, several other studies claim that vitamin $\mathrm{D}$ does not have any impact on ovarian reserve markers $[19,20]$. It is therefore still unclear whether low vitamin D levels play a role in the pathogenesis of PCOS, especially in $\mathrm{AMH}$ regulation. The present study aimed to investigate whether there is a relationship between vitamin D deficiency status and PCOS.

\section{Materials and Methods}

\section{Study design}

This prospective cross-sectional study was carried out at the Reproductive Endocrinology Department of Hitit University Hospital, Çorum, Turkey between January 2, 2015 and September 30, 2016. All participating women gave their written informed consent prior to inclusion in the study. All infertile women with a diagnosis of unexplained infertility admitted to the clinic were included in the study. Infertile women between the ages of 18-35 who were unable to become pregnant after at least 12 months of regular, unprotected intercourse, who did not have poor ovarian reserve, who had normal tubal patency and whose partners had normal semen analysis results met the study's inclusion criteria. The study was approved by the Ethics Committee of Ankara Numune Hospital in accordance with the Declaration of Helsinki, 2013 (20796219-724.087)

Exclusion criteria were smoking, having prior hysterectomy and/or oophorectomy, endometriosis, ovarian masses, hyperprolactinemia, hypogonadotropic hypogonadism, menopause, pregnancy, congenital adrenal hyperplasia, androgen-secreting tumors, and Cushing's syndrome. The exclusion criteria also included systemic disorders such as thyroid and renal dysfunction, and hypertension.

All participants underwent a physical examination, and their weight, height, and waist circumference (WC) measurements were taken. Body mass index (BMI) was calculated by dividing weight (in kilograms) by height (in meters) squared. WC measurements were obtained at the level of the iliac processes and umbilicus, with the same scale used to assess abdominal obesity. Antral follicle count was evaluated by ultrasonography (Toshiba Xario 
100, Toshiba Medical Systems Corporation, Nasu, Japan) using a 7.5-MHz vaginal transducer during routine pelvic evaluation performed by the same clinician on days 2-5 of the menstrual cycle.

A total of 146 infertile women who met the inclusion criteria were divided into two main groups based on their ovarian reserve patterns:

1. normal ovarian reserve pattern (NOR, $n=86)$, and

2. high ovarian reserve pattern (PCOS, $n=60)$.

Using the criteria of the Rotterdam ESHRE-ASRM-sponsored consensus workshop group (2004), PCOS was diagnosed if two of the following three features were present: oligo- and/or anovulation, clinical and/or biochemical signs of hyperandrogenism, and polycystic ovaries on ultrasound (presence of $\geq 12$ follicles measuring 2-9 mm in diameter and/or ovarian volume $>10 \mathrm{~cm}^{3}$ ), after excluding other androgen excess disorders [21]. In addition, all participating women had vitamin $\mathrm{D}$ concentrations of less than $20 \mathrm{ng} / \mathrm{mL}$ as the cut-off value for vitamin D deficiency. Women with NOR and PCOS ovarian patterns were categorized into two groups according to the extent of their vitamin D deficiency as follows:

1. Group A - women with severe vitamin D deficiency $(<10 \mathrm{ng} / \mathrm{mL}, \mathrm{n}=101)$ and

2. Group $B-$ women with mild vitamin D deficiency $(10-20 \mathrm{ng} / \mathrm{mL}, \mathrm{n}=45)$

\section{Specimen collection and assays}

Blood samples were obtained from the antecubital vein of participants between $8 \mathrm{a}$. m. and $10 \mathrm{a}$.m. on menstrual days 2-5 after an overnight fast. Samples were investigated for estradiol (E2), follicle-stimulating hormone (FSH), luteinizing hormone ( $\mathrm{LH})$, total testosterone (TT), 17-hydroxyprogesterone (17-OHP), dehydroepiandrosterone sulfate (DHEA-S), AMH and 25(OH)D. The samples were allowed to clot completely at the room temperature, and then centrifuged at $1000 \times \mathrm{g}$ for 20 minutes within 30 minutes after clotting. Sera were analyzed on a daily basis for E2, FSH, LH, 17-OHP and DHEA-S by electrochemiluminescence immunoassay (ECLIA) method using an auto-analyzer (Cobas 6000, E 601 Roche Diagnostics, GmbH, Mannheim, Germany). The sera were frozen at $-20^{\circ} \mathrm{C}$ within 2 hours for a maximum of 7 days, and then analyzed to measure $\mathrm{AMH}$ levels. $\mathrm{AMH}$ samples were measured with the ECLIA method using an automated analyzer (Cobas 6000, E 601 Roche Diagnostics GmbH, Mannheim, Germany). Comparisons and correlation analysis were performed using all data obtained.

\section{Statistical analysis}

The SPSS (Statistical Packages for the Social Sciences) software programm, version 21 (SPSS Inc. Chicago, IL, USA) was used for all statistical analyses. Continuous variables were first evaluated using the Kolmogorov Smirnov test to test for normality of distribution. Mean differences between study groups were compared by Student's t-test, and Mann-Whitney U-test was used to compare variables that were not normally distributed. Descriptive statistics were expressed as mean ( \pm standard deviation) and number (\%). Spearman's correlation was used to test any linear relationship between 25(OH)D levels and other study variables. A multi- variate regression analysis was performed for each ovarian pattern group to determine preferential effects of 25(OH)D levels. A ROC curve was also constructed. A p-value of less than 0.05 and a confidence interval of $95 \%$ were considered to be statistically significant ( $\triangleright$ Table 4).

\section{Results}

\section{Baseline anthropometric and biochemical characteristics}

The mean age of the total study population was 28.6 years. The anthropometric and biochemical characteristics of women with normal and PCOS ovarian patterns are shown in $>$ Table 1. Age and anthropometric parameters such as BMI, WC, HC and WHR of the participants in the two groups were statistically similar ( $p>0.05$, for all). The E2 level also did not differ between groups $(p=0.059)$. However, there were significant differences between the NOR and the PCOS groups with regard to FSH, LH, TT and DHEA-S $(p<0.001, p=0.005, p<0.001$ and $p=0.005$, respectively). While the women in the NOR group had higher FSH levels, higher LH, TT and DHEA-S levels were found in the PCOS group. As expected, $\mathrm{AMH}$ concentrations were elevated in the sera of women in the PCOS group $(p<0.001)$. However, there were no significant differences in $25(\mathrm{OH}) \mathrm{D}$ levels between both ovarian reserve groups $(p=0.507)$.

\section{Comparisons of anthropometric and biochemical characteristics}

As shown in - Table 2, there were significant differences in the NOR group between Group A $(25(\mathrm{OH}) \mathrm{D}<10 \mathrm{ng} / \mathrm{mL})$ and Group B (25(OH)D: $10-20 \mathrm{ng} / \mathrm{mL}$ ) in terms of anthropometric characteristics including BMI, WC and $\mathrm{HC}(\mathrm{p}<0.001, \mathrm{p}=0.002$ and $\mathrm{p}<0.001$, respectively). In other words, the women with higher levels of vitamin D deficiency had higher adiposity parameters. Mean age and WHR values were statistically similar ( $p>0.05$, for all). In addition, the mean E2 and FSH concentrations were higher in Group B than in Group A ( $p=0.049$ and $p=0.022$, respectively). Study parameters LH, TT, 17-OHP and DHEA-S did not differ significantly between Group A and B ( $p>0.005$, for all). Moreover, the women in both Group A and Group B had similar AMH concentrations $(p>0.005)$.

In the PCOS ovarian pattern group, all study parameters except $\mathrm{BMI}$ and $\mathrm{HC}$ were statistically similar ( $p>0.005$, for all). Mean BMI and $\mathrm{HC}$ values were elevated in women with $25(\mathrm{OH}) \mathrm{D}<10 \mathrm{ng} / \mathrm{mL}$ ( $p=0.034$ and $p=0.032$, respectively).

\section{Correlation and multivariate regression analysis of $25(\mathrm{OH}) \mathrm{D}$ with other study parameters}

The correlations between 25(OH)D and other study parameters, including age, BMI, HC, WHR, E2, FSH, LH, TT, 17-OHP, DHEA-S and $A M H$, in the NOR and PCOS pattern groups are shown in $>$ Table 3. There was a significant but moderate negative correlation between 25(OH)D levels and BMI, WC and HC parameters in the NOR group $(r=-0.359, \quad p<0.001 ; \quad r=-0.301, \quad p=0.005$; $r=-0.340, p<0.001$, respectively). This correlation was not observed in the PCOS group. There was a significant but weak posi- 
- Table 1 Comparison of baseline anthropometric and biochemical characteristics in normal and PCOS ovarian pattern groups.

\begin{tabular}{|c|c|c|c|}
\hline & $\begin{array}{l}\text { Normal ovarian pattern group } \\
(n=86,58.9 \%)\end{array}$ & $\begin{array}{l}\text { PCOS ovarian pattern group } \\
(n=60,41.1 \%)\end{array}$ & $\mathbf{p}$ \\
\hline Age (year) & $28.1 \pm 6.4$ & $27.7 \pm 4.8$ & 0.055 \\
\hline $\mathrm{BMI}\left(\mathrm{kg} / \mathrm{m}^{2}\right)$ & $26.2 \pm 5.1$ & $26.0 \pm 4.9$ & 0.970 \\
\hline$W C(\mathrm{~cm})$ & $89.6 \pm 11.4$ & $90.2 \pm 15.5$ & 0.786 \\
\hline $\mathrm{HC}(\mathrm{cm})$ & $105.0 \pm 10.4$ & $104.8 \pm 10.6$ & 0.920 \\
\hline WHR & $0.9 \pm 0.1$ & $0.9 \pm 0.1$ & 0.661 \\
\hline $\mathrm{E} 2(\mathrm{pg} / \mathrm{mL})$ & $45.9 \pm 22.6$ & $41.1 \pm 33.3$ & 0.059 \\
\hline $\mathrm{FSH}(\mathrm{IU} / \mathrm{L})$ & $7.2 \pm 1.8$ & $6.2 \pm 1.8$ & $0.001^{*}$ \\
\hline $\mathrm{LH}(\mathrm{IU} / \mathrm{L})$ & $5.9 \pm 2.2$ & $7.6 \pm 3.5$ & $0.005^{*}$ \\
\hline$\pi \mathrm{T}(\mathrm{ng} / \mathrm{dL})$ & $28.1 \pm 25.6$ & $30.9 \pm 14.2$ & $0.001^{*}$ \\
\hline 17-OHP (ng/dL) & $1.6 \pm 5.6$ & $1.5 \pm 1.1$ & 0.380 \\
\hline DHEA-S (mcg/dL) & $208.2 \pm 85.9$ & $255.9 \pm 110.6$ & $0.005^{*}$ \\
\hline AMH (ng/dL) & $3.1 \pm 1.9$ & $7.5 \pm 4.5$ & $0.001^{*}$ \\
\hline $25(\mathrm{OH}) \mathrm{D}(\mathrm{ng} / \mathrm{mL})$ & $9.0 \pm 6.0$ & $8.5 \pm 6.7$ & 0.507 \\
\hline \multicolumn{4}{|c|}{$\begin{array}{l}\text { PCOS: polycystic ovary syndrome, BMI: body mass index, WC: waist circumference, HC: hip circumference, WHR: waist-to-hip circumference ratio, } \\
\text { E2: estradiol, FSH: follicle-stimulating hormone, LH: luteinizing hormone, TT: total testosterone, 17-OHP: 17-hydroxyprogesterone, DHEA-S: dehydro- } \\
\text { epiandrosterone sulfate, 25(OH)D: 25-hydroxyvitamin D, AMH: anti-Müllerian hormone }\end{array}$} \\
\hline
\end{tabular}

- Table 2 Comparisons of anthropometric and biochemical characteristics in normal and PCOS pattern groups with vitamin D deficiency status.

\begin{tabular}{|c|c|c|c|c|c|c|}
\hline & \multicolumn{3}{|c|}{ Normal ovarian pattern group } & \multicolumn{3}{|c|}{ PCOS ovarian pattern group } \\
\hline & $\begin{array}{l}\text { Group A } \\
{[25(O H) D<10 \mathrm{ng} / \mathrm{mL}]} \\
(\mathrm{n}=58,67.4 \%)\end{array}$ & $\begin{array}{l}\text { Group B } \\
\text { [25(OH)D: } 10-20 \mathrm{ng} / \\
\mathrm{mL}](\mathrm{n}=28,32.6 \%)\end{array}$ & $\mathbf{p}$ & $\begin{array}{l}\text { Group A } \\
(25(O H) D<10 \mathrm{ng} / \mathrm{mL}) \\
(\mathrm{n}=43,71.7 \%)\end{array}$ & $\begin{array}{l}\text { Group B } \\
\text { [25(OH)D: } 10-20 \mathrm{ng} / \\
\mathrm{mL}](\mathrm{n}=17,28.3 \%)\end{array}$ & $\mathbf{p}$ \\
\hline Age (year) & $29.8 \pm 6.3$ & $31.2 \pm 5.1$ & 0.398 & $27.3 \pm 4.8$ & $28.4 \pm 4.9$ & 0.449 \\
\hline $\operatorname{BMI}\left(\mathrm{kg} / \mathrm{m}^{2}\right)$ & $27.4 \pm 5.4$ & $23.6 \pm 3.4$ & $<0.001^{*}$ & $26.9 \pm 5.1$ & $23.8 \pm 3.4$ & $0.034^{*}$ \\
\hline$W C(\mathrm{~cm})$ & $92.2 \pm 11.4$ & $84.1 \pm 9.3$ & $0.002^{*}$ & $92.3 \pm 16.4$ & $84.9 \pm 11.4$ & 0.095 \\
\hline $\mathrm{HC}(\mathrm{cm})$ & $107.4 \pm 10.8$ & $99.9 \pm 7.3$ & $<0.001^{*}$ & $106.6 \pm 10.2$ & $100.2 \pm 10.2$ & $0.032 *$ \\
\hline WHR & $0.8 \pm 0.1$ & $0.8 \pm 0.1$ & 0.403 & $0.9 \pm 0.1$ & $0.8 \pm 0.1$ & 0.558 \\
\hline $\mathrm{E} 2(\mathrm{pg} / \mathrm{mL})$ & $43.1 \pm 22.5$ & $51.6 \pm 22.1$ & $0.049^{*}$ & $42.4 \pm 37.9$ & $37.7 \pm 16.9$ & 0.825 \\
\hline $\mathrm{FSH}(\mathrm{IU} / \mathrm{L})$ & $6.8 \pm 1.3$ & $8.0 \pm 2.2$ & $0.022^{*}$ & $6.3 \pm 2.0$ & $5.8 \pm 0.9$ & 0.371 \\
\hline $\mathrm{LH}(\mathrm{IU} / \mathrm{L})$ & $5.7 \pm 2.1$ & $6.4 \pm 2.2$ & 0.090 & $7.7 \pm 3.6$ & $7.5 \pm 3.2$ & 0.928 \\
\hline $\mathrm{TT}(\mathrm{ng} / \mathrm{dL})$ & $33.2 \pm 27.9$ & $20.8 \pm 11.5$ & 0.293 & $32.4 \pm 12.3$ & $27.0 \pm 18.1$ & 0.187 \\
\hline 17-OHP (ng/dL) & $1.9 \pm 6.8$ & $0.9 \pm 0.6$ & 0.544 & $0.8 \pm 0.4$ & $1.8 \pm 2.7$ & 0.075 \\
\hline DHEA-S (mcg/dL) & $213.7 \pm 88.4$ & $196.7 \pm 80.6$ & 0.391 & $265.6 \pm 112.2$ & $231.5 \pm 105.8$ & 0.286 \\
\hline $\mathrm{AMH}(\mathrm{ng} / \mathrm{dL})$ & $3.2 \pm 2.0$ & $2.8 \pm 1.7$ & 0.297 & $7.3 \pm 4.3$ & $8 \pm 5.0$ & 0.664 \\
\hline \multicolumn{7}{|c|}{$\begin{array}{l}\text { PCOS: polycystic ovary syndrome, BMI: body mass index, WC: waist circumference, HC: hip circumference, WHR: waist-to-hip circumference ratio, } \\
\text { E2: oestradiol, FSH: follicle stimulating hormone, LH: luteinizing hormone, TT: total testosterone, 17-OHP: 17-hydroxyprogesterone, DHEA-S: dehydro- } \\
\text { epiandrosterone sulfate, 25(OH)D: 25-hydroxyvitamin D, AMH: anti-Müllerian hormone }\end{array}$} \\
\hline \multicolumn{7}{|c|}{ Values are expressed as mean \pm standard deviation. } \\
\hline
\end{tabular}


- Table 3 Correlations between 25(OH)D and other study parameters in the normal and PCOS ovarian pattern groups.

\begin{tabular}{|c|c|c|c|}
\hline \multirow[t]{2}{*}{ Age (year) } & $r$ & 0.103 & -0.064 \\
\hline & $\mathrm{p}$ & 0.346 & 0.628 \\
\hline \multirow[t]{2}{*}{ BMI $\left(\mathrm{kg} / \mathrm{m}^{2}\right)$} & $r$ & $-0.359 *$ & -0.136 \\
\hline & $\mathrm{p}$ & 0.001 & 0.300 \\
\hline \multirow[t]{2}{*}{$W C(\mathrm{~cm})$} & $r$ & $-0.301^{*}$ & -0.126 \\
\hline & $\mathrm{p}$ & 0.005 & 0.336 \\
\hline \multirow[t]{2}{*}{$\mathrm{HC}(\mathrm{cm})$} & $r$ & $-0.340^{*}$ & -0.205 \\
\hline & $\mathrm{p}$ & 0.001 & 0.116 \\
\hline \multirow[t]{2}{*}{ WHR } & $\mathrm{r}$ & -0.042 & 0.001 \\
\hline & $\mathrm{p}$ & 0.698 & 0.994 \\
\hline \multirow[t]{2}{*}{$\mathrm{E} 2(\mathrm{pg} / \mathrm{mL})$} & $r$ & 0.147 & 0.037 \\
\hline & $\mathrm{p}$ & 0.177 & 0.781 \\
\hline \multirow[t]{2}{*}{ FSH (IU/L) } & $r$ & $0.234^{*}$ & -0.118 \\
\hline & $\mathrm{p}$ & 0.030 & 0.367 \\
\hline \multirow[t]{2}{*}{$\mathrm{LH}(\mathrm{IU} / \mathrm{L})$} & $r$ & 0.141 & 0.066 \\
\hline & $\mathrm{p}$ & 0.197 & 0.617 \\
\hline \multirow[t]{2}{*}{$\mathrm{TT}$ (ng/dL) } & $r$ & -0.089 & -0.079 \\
\hline & $\mathrm{p}$ & 0.414 & 0.547 \\
\hline \multirow[t]{2}{*}{ 17-OHP (ng/dL) } & $r$ & -0.002 & $0.339 *$ \\
\hline & $\mathrm{p}$ & 0.983 & 0.008 \\
\hline \multirow[t]{2}{*}{ DHEA-S (mcg/dL) } & $r$ & -0.118 & 0.039 \\
\hline & $\mathrm{p}$ & 0.279 & 0.767 \\
\hline \multirow[t]{2}{*}{ AMH (ng/dL) } & $r$ & -0.112 & 0.027 \\
\hline & $\mathrm{p}$ & 0.307 & 0.836 \\
\hline
\end{tabular}

25(OH)D: 25-hydroxyvitamin D, PCOS: polycystic ovary syndrome, $r$ : Spearman's correlation coefficient, BMI: body mass index, WC: waist circumference, HC: hip circumference, WHR: waist-to-hip circumference ratio, E2: estradiol, FSH: follicle-stimulating hormone, LH: luteinizing hormone, TT: total testosterone, 17-OHP: 17-hydroxyprogesterone, DHEA-S: dehydroepiandrosterone sulfate, AMH: antiMüllerian hormone

${ }^{*} \mathrm{p}$-value is statistically significant $(\mathrm{p}<0.05)$.

tive correlation between $25(\mathrm{OH}) \mathrm{D}$ and $\mathrm{FSH}$ in the NOR group $(r=0.234, p=0.030)$. However, a significant though moderate correlation was observed between $25(\mathrm{OH}) \mathrm{D}$ levels and 17-OHP in the PCOS group $(r=0.339, p=0.008)$. Serum AMH levels were not correlated with $25(\mathrm{OH}) \mathrm{D}$ levels in either the normal or the PCOS ovarian pattern groups $(r=-0.112, p=0.008$ and $r=0.027$, $p=0.836$, respectively).

Multivariate regression showed that the $72.9 \%$ variability in $25(\mathrm{OH}) \mathrm{D}$ levels in the NOR group and the $72.4 \%$ variability in $25(\mathrm{OH}) \mathrm{D}$ levels in the PCOS group could be explained by other study parameters $(F=22.686, p<0.001$ and $F=14.575, p<0.001$ respectively). The interpretation of the coefficients showed that $25(\mathrm{OH}) \mathrm{D}$ levels in both ovarian pattern groups had a significant negative effect on FSH levels ( $p<0.001$, for both). There was no effect of $25(\mathrm{OH}) \mathrm{D}$ on other study parameters. Only AMH measurements were significant enough $(p<0.001)$ to differentiate between PCOS and NOR patterns. In other words, AMH measure-

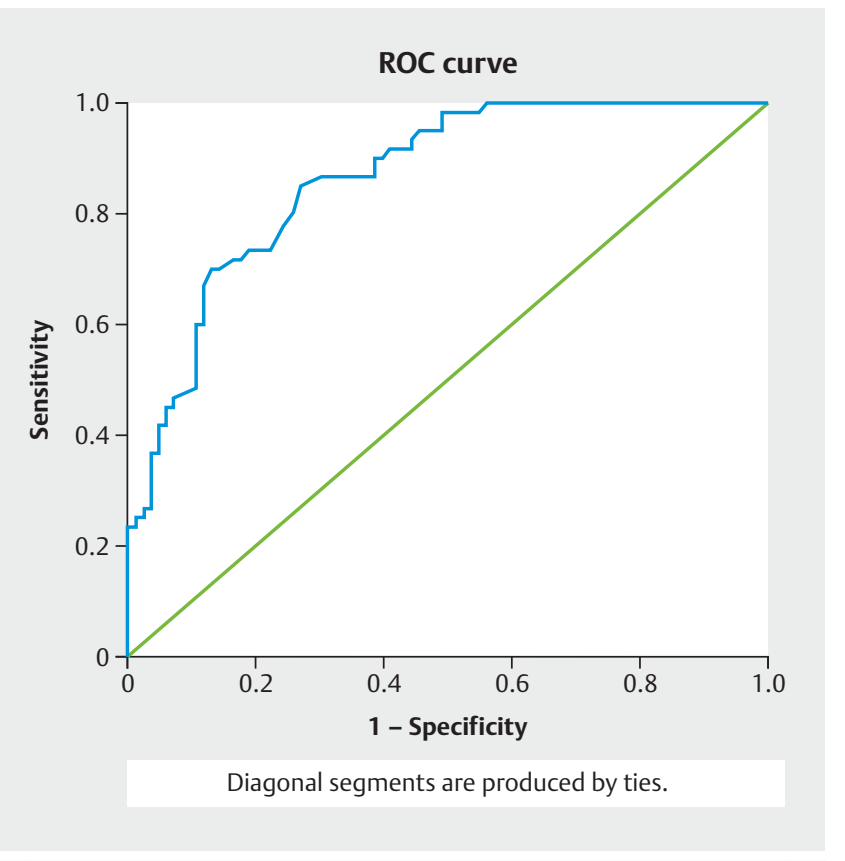

- Fig. 1 A ROC curve of AMH as a diagnostic tool for the diagnosis of PCOS.

ments were more useful than other study parameters to distinguish women with PCOS from women without PCOS. The cut-off point was found to be $3.15 \mathrm{ng} / \mathrm{mL}$ (sensitivity: $90 \%$, specificity: $62 \%$ ), as shown in $>$ Fig. 1 .

\section{Discussion}

This study investigated on low serum 25(OH)D and high AMH levels in infertile women with a diagnosis of PCOS. No differences were found in circulating 25(OH)D levels between infertile women with normal ovarian patterns and women with PCOS. In addition, no correlation between $25(\mathrm{OH}) \mathrm{D}$ and $\mathrm{AMH}$ could be demonstrated in either the NOR or the PCOS pattern group. Therefore, the evidence was insufficient to prove that $25(\mathrm{OH}) \mathrm{D}$ plays a role in the pathogenesis of PCOS.

In the literature, various studies have demonstrated conflicting relationships between serum 25(OH)D levels and PCOS. Although Wehr et al. reported low serum 25(OH)D levels in women with PCOS compared to the control group [12], a significant number of studies have shown that serum $25(\mathrm{OH}) \mathrm{D}$ levels were similar in both of groups $[18,22]$. Interestingly, studies by Mahmoudi et al. [23], Ngo et al. [24], and Panidis et al. [25] have claimed that women with PCOS have significantly higher vitamin D levels compared to controls of similar ages and BMls. Other studies have asserted that vitamin $\mathrm{D}$ deficiency is more prevalent in women with PCOS [12, 26, 27]. In a meta-analysis, the authors noted that $25(\mathrm{OH}) \mathrm{D}$ levels did not differ between women with and women without PCOS [28].

Consistent with our findings, a recent large retrospective study reported that no correlation could be observed between serum $\mathrm{AMH}$ and 25(OH)D levels in PCOS patients and controls [29]. In 
- Table 4 Multivariate regression analysis of 25(OH)D with other study parameters in normal and PCOS pattern groups.

\begin{tabular}{|c|c|c|c|c|c|c|c|c|c|}
\hline \multirow{3}{*}{\multicolumn{2}{|c|}{ Model }} & \multicolumn{4}{|c|}{ Normal ovarian pattern group } & \multicolumn{4}{|c|}{ PCOS ovarian pattern group } \\
\hline & & \multicolumn{2}{|c|}{$\begin{array}{l}\text { Unstandardized } \\
\text { coefficients }\end{array}$} & \multirow{2}{*}{$\begin{array}{l}\text { Standardized } \\
\text { coefficients } \\
\text { Beta }\end{array}$} & \multirow[b]{2}{*}{ p } & \multicolumn{2}{|c|}{$\begin{array}{l}\text { Unstandardized } \\
\text { coefficients }\end{array}$} & \multirow{2}{*}{$\begin{array}{l}\text { Standardized } \\
\text { coefficients } \\
\text { Beta }\end{array}$} & \multirow[b]{2}{*}{$\mathbf{p}$} \\
\hline & & B & Std. error & & & B & Std. error & & \\
\hline \multirow[t]{10}{*}{1} & (Constant) & 17.460 & 3.337 & & 0.000 & 20.911 & 3.540 & & 0.000 \\
\hline & Age (year) & 0.044 & 0.065 & 0.044 & 0.497 & -0.004 & 0.078 & -0.004 & 0.961 \\
\hline & $\operatorname{BMI}\left(\mathrm{kg} / \mathrm{m}^{2}\right)$ & 0.109 & 0.070 & 0.102 & 0.122 & -0.030 & 0.064 & -0.038 & 0.647 \\
\hline & $\mathrm{E} 2(\mathrm{pg} / \mathrm{mL})$ & 0.018 & 0.017 & 0.078 & 0.288 & 0.019 & 0.010 & 0.151 & 0.066 \\
\hline & $\mathrm{FSH}(\mathrm{IU} / \mathrm{L})$ & -2.242 & 0.185 & -0.788 & $<0.001^{*}$ & -1.838 & 0.170 & -0.848 & $<0.001^{*}$ \\
\hline & $\mathrm{LH}(\mathrm{IU} / \mathrm{L})$ & -0.020 & 0.107 & -0.012 & 0.850 & -0.008 & 0.122 & -0.005 & 0.949 \\
\hline & $\mathrm{TT}$ (ng/dL) & 0.009 & 0.028 & 0.025 & 0.750 & -0.001 & 0.011 & -0.010 & 0.905 \\
\hline & 17-OHP (ng/dL) & 0.112 & 0.065 & 0.117 & 0.088 & 0.141 & 0.117 & 0.096 & 0.231 \\
\hline & DHEA-S $(\mu / d L)$ & 0.003 & 0.004 & 0.070 & 0.383 & -0.003 & 0.004 & -0.078 & 0.367 \\
\hline & AMH (ng/dL) & 0.108 & 0.162 & 0.042 & 0.506 & 0.063 & 0.074 & 0.068 & 0.397 \\
\hline & & \multicolumn{4}{|c|}{$R^{2}=0.729$} & \multicolumn{4}{|c|}{$F=14.575 p<0.001$} \\
\hline
\end{tabular}

Std. error: standard error, BMI: body mass index, E2: estradiol, FSH: follicle-stimulating hormone, LH: luteinizing hormone, TT: total testosterone, 17-OHP: 17-hydroxyprogesterone, DHEA-S: dehydroepiandrosterone sulfate, 25(OH)D: 25-hydroxyvitamin D, AMH: anti-Müllerian hormone

${ }^{*} \mathrm{p}$-value is statistically significant $(\mathrm{p}<0.05)$.

that study which involved 340 predominately Caucasian women, serum 25(OH)D levels appeared to be unrelated to serum AMH levels. No correlation was observed between serum 25(OH)D and AMH levels. Furthermore, women with different ovarian reserve status showed no significant differences in their serum 25(OH)D concentrations. In addition, a meta-analysis found that $25(\mathrm{OH}) \mathrm{D}$ levels did not differ between women with and women without PCOS [30]. In contrast, Merhi et al. reported a positive and statistically significant correlation between serum 25(OH)D and AMH levels in women over 40 years of age [31]. However, serum AMH levels in this age group were very low and were sometimes below measurement levels. The study by Dennis et al. also reported a positive relationship between 25(OH)D and AMH levels [32]. However, this study had some methodological weaknesses, including low participant numbers.

In the present study, serum TT levels were significantly higher in the PCOS pattern group. These findings are consistent with studies by Tehrani et al. [33], Skatba et al. [34] and Bakeer et al. [35]. This may be attributable to the increased thickness of theca layers in PCOS patients, leading to excessive steroidogenic activity [36], and to elevated AMH levels, which have an inhibitory effect on FSH-induced aromatase activity [37]. Earlier studies demonstrated a relationship between vitamin $D$ deficiency status and an imbalance in serum DHEA-S and TT levels $[10,30]$. In a study examining serum $\mathrm{FSH}, \mathrm{LH}$, dehydroepiandrosterone, testosterone and 25(OH)D levels in females with PCOS, a significant correlation was found between 25(OH)D levels and LH/FSH rates, but no correlation with androgens was detected [38]. The authors of that study suggested that vitamin D deficiency was related to hormonal dysregulation in women with PCOS.
When 25(OH)D was compared with measured adiposity characteristics based on the extent of vitamin $\mathrm{D}$ deficiency, significant differences were found between 25(OH)D levels and BMI in both the normal and PCOS ovarian pattern groups. Women with higher BMI were more likely to have lower $25(\mathrm{OH}) \mathrm{D}$ levels. In parallel to these findings, a significant inverse relationship between BMI and serum $25(\mathrm{OH}) \mathrm{D}$ concentrations has been confirmed in various studies [10, 13, 14, 22, 39]. Numerous studies have reported an inverse relationship between obesity parameters (BMI, body fat and waist measurements) and serum 25(OH)D levels. [12 - 14, 39].

According to a large body of evidence, obesity is associated with lower serum $25(\mathrm{OH}) \mathrm{D}$ concentrations. This association is likely to be due to volumetric dilution into greater volumes of serum, fat, muscle and liver. Obese individuals tend to be exposed to less sunlight, leading to insufficient biosynthesis of $25(\mathrm{OH}) \mathrm{D}$ generated through the skin [22]. Moreover, obesity is more widespread in women with PCOS $[39,40]$. It is possible that low serum $25(\mathrm{OH}) \mathrm{D}$ concentrations are not the cause but a consequence of obesity. Low 25(OH)D and genes related to low 25(OH)D have been shown to have a minor effect on obesity [41].

The present study did not demonstrate significantly higher BMI values in either group. However, women with PCOS may be expected to have higher measured values of anthropometric characteristics compared to those without PCOS, as reported in a variety of studies [34,42]. These results alone, however, are not adequate to establish a causal relationship between high measured values of anthropometric characteristics and PCOS [43].

In the present study, the mean AMH level detected was significantly higher in the PCOS group. Several other studies have also reported an increased level of AMH in PCOS patients [34, 44, 45]. The increase in $\mathrm{AMH}$ concentrations could be attributable to in- 
creased numbers of preantral and antral follicles. This increase is caused either by the increase in $\mathrm{AMH}$ concentrations or is due to signalling abnormalities in the follicles [46]. Serum AMH levels appear to be related to the severity of PCOS $[47,48]$. The literature contains a number of recent studies aiming to establish a threshold for AMH in the diagnosis of PCOS [49-53]. AMH threshold values varied widely across these studies. However, serum AMH concentrations were generally in the upper range of normal or even elevated in women with PCOS [54]. Although AMH is not currently a generally accepted parameter in the laboratory workup of PCOS, serum AMH concentration is a valuable tool for diagnosing PCOS. The lack of international standards for serum AMH assays, mostly due to technical issues, appears to be the reason for the lack of a definitive consensual threshold.

In the existing literature, the findings of studies evaluating the relationship between vitamin D status and PCOS were contradictory. The small sample sizes, lack of adjustment for confounders, differences in the methodology used to measure serum 25(OH)D, duration of interventions, and lack of an optimal serum $25(\mathrm{OH}) \mathrm{D}$ level in the general population might be potential causes.

Vitamin D deficiency was detected in almost all infertile women included in the study according to the reference range of the hospital laboratory. No adequate number of infertile women without vitamin D deficiency could be found during the study period because, as in other parts of the world, vitamin D deficiency is endemic in the Turkish female population. This shortfall is a limitation of our study. The lack of standardized lifestyle conditions in terms of dietary habits and clothing styles of the participants could also be considered a limitation of this study. However, few studies have investigated the relationship between serum 25 $(\mathrm{OH}) \mathrm{D}$ levels and serum AMH levels based on ovarian pattern. Investigating this issue is a strength of this study. All of the participants in the study were infertile; vitamin D deficiency status is likely to become more of a focus for women seeking fertility care. The present study's focus on this deficiency is another of its strengths.

In summary, the present study revealed no difference in serum 25(OH)D and AMH levels in women with and without PCOS. In addition, no correlation was found between 25(OH)D and AMH levels in women with PCOS or their matched controls. Due to the heterogeneity of the results in other studies, drawing an informed conclusion may be difficult. Further investigations are needed to determine the potential association between serum 25(OH)D levels and PCOS.

\section{Conflict of Interest}

The authors declare that they have no conflict of interest.

\section{References}

[1] Ehrmann DA. Polycystic ovary syndrome. N Engl J Med 2005; 352: $1223-$ 1236

[2] Üstüner I, Sönmezer M, Atabekoğlu C et al. Chronic Inflammation in Women with Polycystic Ovarian Syndrome. Gynecol Obstet Reprod Med 2006; 12: 180-185
[3] Qi X, Pang Y, Qiao J. The role of anti-Müllerian hormone in the pathogenesis and pathophysiological characteristics of polycystic ovary syndrome. Eur J Obstet Gynecol Reprod Biol 2016; 199: 82-87

[4] Parahuleva N, Pehlivanov B, Orbecova M et al. Serum levels of anti-mullerian hormone in women with polycystic ovary syndrome and healthy women of reproductive age. Akush Ginekol (Sofiia) 2013; 52 (Suppl. 1): $16-23$

[5] Vieth R. Vitamin D supplementation, 25-hydroxyvitamin D concentrations, and safety. Am J Clin Nutr 1999; 69: 842-856

[6] Parikh G, Varadinova M, Suwandhi P et al. Vitamin D regulates steroidogenesis and insulin-like growth factor binding protein-1 (IGFBP-1) production in human ovarian cells. Horm Metab Res 2010; 42: 754-757

[7] Muscogiuri G, Mitri J, Mathieu C et al. Mechanisms in endocrinology: vitamin $\mathrm{D}$ as a potential contributor in endocrine health and disease. Eur J Endocrinol 2014; 17: R101-R110

[8] Thomson RL, Spedding S, Buckley JD. Vitamin D in the aetiology and management of polycystic ovary syndrome. Clin Endocrinol (Oxf) 2012; 77: 343-350

[9] Tsakova AD, Gateva AT, Kamenov ZA. 25(OH) vitamin D levels in premenopausal women with polycystic ovary syndrome and/or obesity. Int J Vitam Nutr Res 2012; 82: 399-404

[10] Yildizhan R, Kurdoglu M, Adali E et al. Serum 25-hydroxyvitamin D concentrations in obese and non-obese women with polycystic ovary syndrome. Arch Gynecol Obstet 2009; 280: 559-563

[11] Solak I, Cihan FG, Mercan S et al. Evaluation of 25-Hydroxyvitamin D Levels in Central Anatolia, Turkey. Biomed Res Int 2018; 2018: 4076548

[12] Wehr E, Trummer O, Giuliani A et al. Vitamin D-associated polymorphisms are related to insulin resistance and vitamin D deficiency in polycystic ovary syndrome. Eur J Endocrinol 2011; 164: 741-749

[13] Li HW, Brereton RE, Anderson RA et al. Vitamin D deficiency is common and associated with metabolic risk factors in patients with polycystic ovary syndrome. Metabolism 2011; 60: 1475-1481

[14] Wehr E, Pilz S, Schweighofer $N$ et al. Association of hypovitaminosis D with metabolic disturbances in polycystic ovary syndrome. Eur J Endocrinol 2009; 161: 575-582

[15] Rashidi B, Haghollahi F, Shariat M et al. The effects of calcium-vitamin D and metformin on polycystic ovary syndrome: a pilot study. Taiwan J Obstet Gynecol 2009; 48: 142-147

[16] Firouzabadi Rd, Aflatoonian A, Modarresi S et al. Therapeutic effects of calcium and vitamin D supplementation in women with PCOS. Complement Ther Clin Pract 2012; 18: 85-88

[17] Gallea M, Granzotto M, Azzolini S et al. Insulin and body weight but not hyperandrogenism seem involved in seasonal serum 25-OH-vitamin D3 levels in subjects affected by PCOS. Gynecol Endocrinol 2014; 30: 739745

[18] Mahmoudi T. Genetic variation in the vitamin D receptor and polycystic ovary syndrome risk. Fertil Steril 2009; 92: 1381-1383

[19] Görkem Ü, Küçükler F, Toğrul C et al. Vitamin D Does not Have Any Impact on Ovarian Reserve Markers in Infertile Women. Gynecol Obstet Reprod Med 2017; 23: 79-83

[20] Shapiro AJ, Darmon SK, Barad DH et al. Vitamin D levels are not associated with ovarian reserve in a group of infertile women with a high prevalance of diminished ovarian reserve. Fertil Steril 2018; 110: 761-766.e1

[21] Rotterdam ESHRE/ASRM-Sponsored PCOS Consensus Workshop Group. Revised 2003 consensus on diagnostic criteria and long-term health risks related to polycystic ovary syndrome. Fertil Steril 2004; 81: 19-25

[22] Kim J], Choi YM, Chae SJ et al. Vitamin D deficiency in women with polycystic ovary syndrome. Clin Exp Reprod Med 2014; 41: 80-85

[23] Mahmoudi T, Gourabi H, Ashrafi M et al. Calciotropic hormones, insulin resistance, and the polycystic ovary syndrome. Fertil Steril 2010; 93: 1208-1214 
[24] Ngo DT, Chan WP, Rajendran S et al. Determinants of insulin responsiveness in young women: impact of polycystic ovarian syndrome, nitric oxide, and vitamin D. Nitric Oxide 2011; 25: 326-330

[25] Panidis D, Balaris C, Farmakiotis D et al. Serum parathyroid hormone concentrations are increased in women with polycystic ovary syndrome. Clin Chem 2005; 51: 1691-1697

[26] Wehr E, Trummer O, Giuliani A et al. Vitamin D-associated polymorphisms are related to insulin resistance and vitamin D deficiency in polycystic ovary syndrome. Eur J Endocrinol 2011; 164: 741-749

[27] Mazloomi S, Sharifi F, Hajihosseini R et al. Association between hypoadiponectinemia and low serum concentrations of calcium and vitamin D in women with polycystic ovary syndrome. ISRN Endocrinol 2012; 2012: 949427

[28] He C, Lin Z, Robb SW et al. Serum vitamin D levels and polycystic ovary syndrome: a systematic review and meta-analysis. Nutrients 2015; 7: 4555-4577

[29] Pearce K, Gleeson K, Tremellen K. Serum anti-Mullerian hormone production is not correlated with seasonal fluctuations of vitamin $D$ status in ovulatory or PCOS women. Hum Reprod 2015; 30: 2171-2177

[30] He C, Lin Z, Robb SW et al. Serum vitamin D levels and polycystic ovary syndrome: a systematic review and meta-analysis. Nutrients 2015; 7: 4555-4577

[31] Merhi ZO, Seifer DB, Weedon J et al. Circulating vitamin D correlates with serum antimüllerian hormone levels in late-reproductive-aged women: Women's Interagency HIV Study. Fertil Steril 2012; 98: 228-234

[32] Dennis NA, Houghton LA, Jones GT et al. The level of serum anti-Müllerian hormone correlates with vitamin D status in men and women but not in boys. J Clin Endocrinol Metab 2012; 97: 2450-2455

[33] Tehrani FR, Simbar M, Tohidi M et al. The prevalence of polycystic ovary syndrome in a community sample of Iranian population: Iranian PCOS prevalence study. Reprod Biol Endocrinol 2011; 9: 39

[34] Skałba P, Cygal A, Madej P et al. Is the plasma anti-Müllerian hormone (AMH) level associated with body weight and metabolic, and hormonal disturbances in women with and without polycystic ovary syndrome? Eur J Obstet Gynecol Reprod Biol 2011; 158: 254-259

[35] Bakeer E, Radwan R, El Mandoury A et al. Anti-Müllerian Hormone as a Diagnostic Marker in Egyptian Infertile Polycystic Ovary Syndrome Females: Correlations with Vitamin D, Total Testosterone, Dyslipidemia and Anthropometric Parameters. J Med Biochem 2018; 37: 448-455

[36] Wood JR, Ho CK, Nelson-Degrave VL et al. The molecular signature of polycystic ovary syndrome (PCOS) theca cells defined by gene expression profiling. J Reprod Immunol 2004; 63: 51-60

[37] Dewailly D, Andersen CY, Balen A et al. The physiology and clinical utility of anti-Mullerian hormone in women. Hum Reprod Update 2014; 20 : 370-385

[38] Kozakowski J, Kapuścińska R, Zgliczyński W. Associations of vitamin D concentration with metabolic and hormonal indices in women with polycystic ovary syndrome presenting abdominal and gynoidal type of obesity. Ginekol Pol 2014; 85: 765-770

[39] Muscogiuri G, Policola C, Prioletta A et al. Low levels of 25(OH)D and insulin-resistance: 2 unrelated features or a cause-effect in PCOS? Clin Nutr 2012; 31: 476-480
[40] Savastano S, Valentino R, Di Somma C et al. Serum 25-hydroxyvitamin D Levels, phosphoprotein enriched in diabetes gene product (PED/PEA-15) and leptin-to-adiponectin ratio in women with PCOS. Nutr Metab (Lond) 2011; 8: 84

[41] Vimaleswaran KS, Berry DJ, Lu C et al. Causal relationship between obesity and vitamin D status: bi-directional Mendelian randomization analysis of multiple cohorts. PLoS Med 2013; 10: e1001383

[42] Legro RS. Obesity and PCOS: Implications for diagnosis and treatment. Semin Reprod Med 2012; 30: 496-506

[43] Legro RS, Arslanian SA, Ehrmann DA et al. Diagnosis and treatment of polycystic ovary syndrome: an Endocrine Society clinical practice guideline. J Clin Endocrinol Metab 2013; 98: 4565-4592

[44] Lie F, Schipper I, de Jong FH et al. Serum anti-Müllerian hormone and inhibin $B$ concentrations are not useful predictors of ovarian response during ovulation induction treatment with recombinant follicle-stimulating hormone in women with polycystic ovary syndrome. Fertil Steril 2011; 96: 459-463

[45] Laven JS, Mulders AG, Visser JA et al. Anti-Müllerian hormone serum concentrations in normoovulatory and anovulatory women of reproductive age. J Clin Endocrinol Metab 2004; 89: 318-323

[46] Maciel GA, Baracat EC, Benda JA. Stockpiling of transitional and classic primary follicles in ovaries of women with polycystic ovary syndrome. J Clin Endocrinol Metab 2004; 89: 5321-5327

[47] Pigny P, Merlen E, Robert $Y$ et al. Elevated serum level of anti-mullerian hormone in patients with polycystic ovary syndrome: relationship to the ovarian follicle excess and to the follicular arrest. J Clin Endocrinol Metab 2003; 88: 5957-5962

[48] Piouka A, Farmakiotis D, Katsikis I et al. Anti-Mullerian hormone levels reflect severity of PCOS but are negatively influenced by obesity: relationship with increased luteinizing hormone levels. Am J Physiol Endocrinol Metab 2009; 296: E238-E243

[49] Tal R, Seifer DB, Khanimov M et al. Characterization of women with elevated antimüllerian hormone levels $(\mathrm{AMH})$ : correlation of $\mathrm{AMH}$ with polycystic ovarian syndrome phenotypes and assisted reproductive technology outcomes. Am J Obstet Gynecol 2014; 211: 59.e1-59.e8

[50] Sova H, Unkila-Kallio L, Tiitinen A et al. Hormone profiling, including anti-Müllerian hormone (AMH), for the diagnosis of polycystic ovary syndrome (PCOS) and characterization of PCOS phenotypes. Gynecol Endocrinol 2019. doi:10.1080/09513590.2018.1559807

[51] Yue CY, Lu LK, Li M et al. Threshold value of anti-Mullerian hormone for the diagnosis of polycystic ovary syndrome in Chinese women. PLoS One 2018; 13: e0203129

[52] Wongwananuruk T, Panichyawat N, Indhavivadhana S et al. Accuracy of anti-Müllerian hormone and total follicles count to diagnose polycystic ovary syndrome in reproductive women. Taiwan J Obstet Gynecol 2018; 57: 499-506

[53] Arslan S, Akdevelioğlu Y. The Relationship Between Female Reproductive Functions and Vitamin D. J Am Coll Nutr 2018; 37: 546-551

[54] Nachtigal MW, Ingraham HA. Bioactivation of Mullerian inhibiting substance during gonadal development by a kex2/subtilisin-like endoprotease. Proc Natl Acad Sci U S A 1996; 93: 7711-7716 